further improvements among more severely ill or difficult to treat patients, complementing the 'average' patients studied by Fleischhacker et al. Hopefully, readers will consider the full report before reaching conclusions about the potential impact of long-acting risperidone for their particular patients.

FLEISCHHACKER, W.W., EERDEKENS, M., KARCHER, K., et al (2003) Treatment of schizophrenia with longacting injectable risperidone: a 12-month open-label trial of the first long-acting second-generation antipsychotic. Journal of Clinical Psychiatry, 64, 10, 1250-1257.

John M. Kane The Zucker Hillside Hospital, Glen Oaks, NY， *Robert Lasser Janssen Medical Affairs, LLC,Titusville, NJ 08560-0200. E-mail: rlasser@janus.jnj.com, Edward Crumbley Janssen Medical Affairs, LLC, Titusville, NJ

\section{Perverse incentives}

Whether or not the incentive to be able to retire early from what your survey confirms to be an overworked and undervalued profession is 'perverse' (Psychiatric Bulletin, April 2004, 28, 130 132 ) is a matter for debate. Nevertheless, many psychiatrists will undoubtedly have taken it into account when choosing their career. More to the point, many mental health officers (MHOs) will have made important financial planning decisions based upon a 'guarantee by law' (A guide to the National Health Service (NHS) pensions scheme, National Health Service Pensions Agency, 2001) that such an entitlement will remain in place. Given that there may be moves by the government to change the law and hence remove such a guarantee, do the author not consider it unwise to describe what many consider to be one of the few 'perks' of psychiatry in such a way?

Given the substantial financial incentives of non-NHS work, have the authors not considered the potentially disastrous consequences for an already strained profession that the removal of $\mathrm{MHO}$ status might lead to?

Mike Cooper Consultant in General Adult Psychiatry, Rotherham District General Hospital

\section{Retirement}

Pleased initially simply to have avoided the cut on being an 'older' psychiatrist (Mears et al, Psychiatric Bulletin, 2004, 28, 130 132), I reflect that past 45 , I enjoy my job, have a great team of colleagues and rarely complain about my income - only my outgoings. Having left two consultant posts behind me (happily filled), I hope to train somebody to jump aboard when I shuffle off at 55 or 56 . This may be too early to retire from life, but as the old joke observes, nobody lies on his deathbed mourning that they hadn't spent more time in the office. Unless the world is turned upside down, there will be no shortage of part-time, locum, medicolegal and private work to do should I wish to continue as a psychiatrist. If I'm spared, I might prefer a life change.

The average age of the sample was 56 , so it is unsurprising that those still registered and compos mentis were still working. I wonder how many of the sample with mental health officer status planned to work beyond the point at which they achieve maximum pension? Nobody I know has stayed more than a year or two. If appearances are anything to go by, most of them look 10 years younger within months of retirement. I will be surprised if your columns are full of post-retirement psychiatrists bemoaning their premature trips to the sun: they'll all be too busy to write.

Andrew McBride Consultant Psychiatrist, Specialist CommunityAddictions Service, The Rectory Centre, Rectory Road, Oxford OX4 1BU, e-mail: andrew.mcbride@oxmhc-tr.nhs.uk

\section{Sociological support for importance of complementary and alternative medicine (CAM)}

The timely article by Bhugra et al (Psychiatric Bulletin, February 2004, 28 36-39) may not be welcomed by all readers. Therefore, I would like to support their view that psychiatrists - and indeed other physicians - should take an interest in whatever their patients resort to for relief of symptoms. For additional reading, I recommend a chapter by Goldstein (1999). Already more than 10 years ago, it was estimated that Americans made considerably more visits to unconventional providers than to all primary care physicians. By so doing, they spent $\$ 13.7$ billion more than they spent out of pocket on conventional care that same year. Some insurance companies and health maintenance organisations offer coverage for some forms of alternative care. Listings in the Healthy Yellow Pages for Los Angeles are hilarious and informative alike.

In the 16th century, few liked to believe that the earth is not the centre of the universe. Now, most medically trained people prefer to perceive themselves as central to providing health care. The perspective seems to be different for many on the receiving end.

GOLDSTEIN, M. S. (1999) The growing acceptance of complementary and alternative medicine. In Handbook of Medical Sociology (ed C. E. Bird, P. Conrad \& A. M. Fremont), pp. 284-297. Harlow: Pearson Education Limited.

CorneliaThiels Professor of Social Medicine Department of Social Sciences, University of Applied Sciences, Bielefeld, Germany

\section{Liaison psychiatry}

would like to echo the view of liaison psychiatry expressed by Dr Bolton (Psychiatric Bulletin, April 2004, 28, 149). When I moved to Wolverhampton nearly 6 years ago, there was a very well thought of nurse-led liaison psychiatry service which as well as providing an excellent response to the local accident and emergency department also was developing links with particular specialties. The service had been based at the general hospital along with the psychiatric beds, but when the latter were relocated to a purpose-built facility on a different site in December 2002, the liaison service lost its accommodation on site. Foreseeing this, we had provided a detailed service specification well in advance of the move; we were later told this had been 'lost', so resupplied it. At around the same time, there was a change in management as we were absorbed into the primary care trust and senior management became very interested at the point where it became clear that there had never been a service level agreement with the acute trust. The service was entirely funded from mental health, apart from one seven session psychology post that continues to be funded by the acute trust.

A number of meetings have taken place between senior management and clinicians between the primary care trust and the acute trust but these have proved frustratingly inconclusive. Despite the fact that my one or two sessions of input to the service remain significantly below the recommended norm of about two full-time equivalents for the size of the hospital, the team has continued to provide a wellthought of service which is valued by clinicians in the acute trust. Goodwill has not translated into funding however, and because the primary care trust has entered the new financial year short of cash, it is proposing to cut two nursing posts and redeploy the third into another needy area of mental health. The thinking behind this is presumably along the lines: 'If it ain't broke... . let's tinker with it until it is, and then we can abolish it ....'

Teresa Black Consultant Psychotherapist, Clevelands House, 10/12 Tettenhall Road, Wolverhampton, WV1 4SA

\section{The objective structured clinical examination (OSCE)}

The objective structured clinical examination was introduced in spring 2003 as a more comprehensive and a fairer method of assessment of the clinical abilities of the candidates for the Part I MRCPsych. It was thought that this method would examine candidates' clinical abilities over more clinical subjects than the traditional long case could achieve. Instead of having 
7?

columns only two examiners, the candidate is examined over 12 different areas by 12 different examiners. We would have grave difficulty in satisfying examiners as to our competence in this type of exam!

The time available to trainees to perform what we would regard as difficult and complex investigations is not sufficient. It would appear that we should be teaching our trainees that it is right to perform quick, perfunctory, examinations of patients, so that 'snap' diagnoses can be made. Our experience in psychiatry would indicate that this is not a skill that should be seen as beneficial or helpful, either to the psychiatrist or their patient.

It would appear that the OSCE format has been 'borrowed' from the MRCP exam of the Royal College of Physicians. While in general medicine you can make an exam centre around specific clinical tasks, in psychiatry this is much more difficult and can lead to serious problems in understanding. Psychiatry surely is about the whole person; physical, psychological and social. This bio-psycho-social model of psychiatry makes it necessary for assessing psychiatrists to see psychiatric symp toms within their physical, psychological and social context. It is impossible to even attempt such an evaluation within the 6 minutes a candidate has with a patient

We may live in the age of fast food, fast communications and fast turnover of patients on our wards, but is 'fast psychiatry' something the College should actively promote? We think not. We are still in an age where accurate diagnosis of all aspects of our patients' problems requires careful thought and often time consuming examination. For the College to use this type of format in its profes sional exam appears to us to be badly thought through, and in urgent need of review.

Alma Yak Senior House Officer

*W. K. Abdul-Hamid Consultant Psychiatrist The Linden Centre, Woodlands Way, Broomfield, Chelmsford, Essex CM17LF, Roy Chad Consultant Psychiatrist

\section{Domiciliary phlebotomy}

As a practising old age psychiatrist in another part of Mersey Care Trust, I read Darley et al's article on domiciliary phlebotomy for elderly patients (Psychiatric Bulletin, April 2004, 28, 120-122) with interest.

I agree with the authors' conclusion that domiciliary phlebotomy can be a viable method of performing blood inves tigations in old age psychiatry. However, the financial savings demonstrated in the study might be hard to replicate in other parts of the trust or in other National Health Service trusts.
The main reason for the low cost appears to be minimum distance travelled in each visit (1.4 miles return journey). The average return journey in my patch would be 6 miles. For the 511 visits done in the study, it would mean a total journey of 3066 miles (compared with 730 miles in the study) and it would cost $f 1165$ on travel for the service (compared with $\mathrm{f} 285$ in the study).

The financial savings in travel cost would therefore be only $f 130$ (compared with $\mathrm{f} 1010$ in the study).

The expenses also do not seem to take into account the cost of employment of the phlebotomist. We have trained one of the support workers in taking blood who provides the domiciliary service for patients unable to attend the community clinic. He also provides the service in the clinic for other patients who attend the clinic for out-patient appointments, thus not necessitating ambulance journeys purely for phlebotomy.

Thus, we have neither needed to separately appoint a community phlebotomist and also have reduced unnecessary ambulance costs by making him available on clinic days.

Sudip Sikdar Consultant in Old Age Psychiatry, Mersey Care NHS Trust, Waterloo Day Hospital, Park Road, Waterloo, Liverpool L22 3XR

\section{the college}

\section{Child Abuse and Neglect and Mental Health Services}

Council Report CR120

October 2003, Royal College of Psychiatrists, f5.00, $32 \mathrm{pp}$

Child abuse and neglect are now recognised as being 'everybody's business'. Aspects of prevention, recognition, assessment and treatment of child maltreatment all fall within the province of the various branches of psychiatry. This document reviews these responsibilities.

Following a definition of child abuse and neglect, the document summarises key documents that have been published recently in England, and their equivalents in Scotland, Wales and Northern Ireland. They include legislation (The Children Act 1989) and government guidance documents accompanying this legislation: Working Together (1999), the Assessment Framework (2000) and Safeguarding Children in Whom Illness is Fabricated or Induced.

Following Lord Laming's enquiry into the death of Victoria Climbie, the government published What To Do If You're Worried A Child Is Being Abused (2003). Two documents deal with evidence of children and other vulnerable witnesses in criminal trial and provision of therapy for child witnesses prior to a criminal trial. The Carlile Review, published by the Welsh Assembly in 2002, highlights the vulnerability of children and young people treated and cared for in psychiatric inpatient units. Several documents deal with domestic violence and with patients as parents.

Several issues of practice are addressed. They include multiagency work; culture, ethnicity and gender; confidentiality; the storing of video recordings; and allegations against staff.

A section on selected clinical issues highlights those which were considered to be of particular salience in the field of child protection: vulnerability - including learning and other disabilities and looked after children; transition from victim to abuser; domestic violence; sexual abuse by adolescents; sexual abuse by women; organised abuse; fabricated or induced illness; and the effects on children of adult mental disorder and substance abuse.

The section on research findings includes effects of abuse and breaking the cycle of abuse. These were selected as being of especial relevance to psychiatrists encountering child abuse.
The section on types of professional involvement includes general guidance as well as guidance for specific specialties. The sections discuss the principles of recognition of abuse, investigation and assessment of risk to children, assessment of treatment needs and provision; and medico-legal work.

Lastly, there is a brief mention of training needs.

The report is available for purchase from the College Book Sales Office and can be downloaded from the website: www.rpsych.ac.uk

\section{Proposal for a Special Interest Group in Social Science and Psychiatry}

Procedure for establishing a Special Interest Group

(1) Any member wishing to establish a Special Interest Group shall write to the Registrar with relevant details

(2) The Registrar shall forward the application to Council.

(3) If Council approves the principle of establishing such a Special Interest Group then it will direct the Registrar to place a notice in the Bulletin, or its 